\title{
Toward a Greater Understanding: Utilizing Book Discussions to Effectively Engage Students in the Exploration of Women and Leadership Issues
}

\author{
Heather Inez Ricks Scott, Ph.D. \\ Assistant Professor of Leadership Studies \\ Kennesaw State University \\ hscott18@kennesaw.edu
}

\begin{abstract}
This article examines the use of a book discussion as an instructional tool for developing leadership competency skills in female university students. A book discussion centered on Sheryl Sandberg's book Lean In was held as a means to conceptualize discourse regarding leadership issues in the arena of women and leadership in a multidisciplinary campus wide symposium. In an effort to assess the effectiveness of such a program to learn about leadership issues, student commentary was collected during the discussion via an audio recording device.

A qualitative exploration of the resulting commentary focused on this initiative as an effort to provide insight into the efficacy of book discussions as a best practice for facilitating the engagement of students in the exploration of leadership issues. As leadership educators seek to develop pedagogical tools that catalyze transformative learning, research regarding tools and methods by which faculty equip students to explore leadership becomes increasingly critical.
\end{abstract}

\section{Introduction}

This qualitative inquiry explores the use of book discussions to prepare college and university students to effectively engage in the exploration of women and leadership issues. The book discussion format was utilized as a co-curricular instructional tool in a women and leadership symposium held in recognition of Women's History Month at a large suburban, southeastern university. This inaugural event served as an opportunity for students, faculty, and staff to share in discourse about women and leadership issues from a broad array of perspectives. This exploration of the concept includes an overview of book discussions, the process by which the campus book discussion was developed, and qualitative data in the form of participant responses.

\section{Literature Review}

Women and Leadership. Women are securing more leadership roles, albeit at a slow pace. As a result of this increase more women are serving as leaders in both the United States and abroad. As the emphasis for business shifts to a global focus, leadership is also changing from a focus on part of the world to a focus on the entire world. Kanter (1994) states that in a global economy, "meritocracy- letting talent rise to the top regardless of where it is found and whether it is male or female- is essential to business success" (p.89). Adler, Brody, and Osland 
(2000) assert that global leaders must be able to articulate a globally encompassing vision and to communicate that vision to people around the world in ways that inspire them to work together. As corporations realize the importance of being globally competent, particularly as it pertains to developing women as leaders, a strong emphasis continues to be placed on leadership development programs that build global competency and leadership skills. Referencing data from a study regarding the success of women in senior management roles Werhane (2000) suggests that the leadership styles that we see most often exemplified in women best fit the kind of global governance most appropriate for our changing world. This perspective is but one example of the importance of developing college students to be globally competent citizens and cognizant of the impact of gender on leadership issues. When we engage students in learning opportunities that focus on these issues we in turn impact their understanding and development of leadership skills.

Book Discussions. Learning experiences that afford students an opportunity to share their stories and connect with those of others is particularly effective in the process of making meaning of theoretical concepts. Long (2003) places specific emphasis on the efficacy of reading groups and discussion as a means to offer support to women in the learning process. This aforementioned support creates the ability to explore one's identity and the complexities of the identity development process over time. Long indicates that the dynamics of a group discussion may provide participants with the benefit of exploring shared perspectives along with being challenged by multiple perspectives as they make meaning of the reading. Switzer and Barclay (2012) further posits that the critical thinking skills developed in the setting of the book discussion helps students to evaluate their own perspectives as well as the perspectives of others. Due to the uncharted territory that many female leaders face, this approach can prove to be valuable to those seeking to understand the vast array of topics associated with the scholarship of women and leadership.

Teaching is an art and instructors must rely on a variety of methods to engage learners (Boyer, 1997). One such method is the discussion format, specifically that of a book discussion. Larson (1997) defines discussion as a structured conversation among participants who present, examine, compare and understand similar and diverse ideas about an issue. As indicated by Larson, scholars have found that discussions are an effective way to promote higher-level thinking, develop student perspectives, and advance student capability for moral questioning.

Switzer and Barclay identify several benefits for students, instructors, and practitioners in their research on book clubs. As illustrated from the results of a study conducted by the two, they maintain that academic book clubs may be a way to engage students and develop critical thinking skills. Their study evaluated a book club program for business students and also indicated that book clubs (a group of individuals coming together to discuss a common reading) may provide an opportunity for instructors to assess their students' reasoning and problem solving skills. Switzer and Barclay also theorize that discussions aid students in their ability to analyze, synthesize, and evaluate situations. The authors indicate that this process provides students with an opportunity to connect the reading with life experiences and course concepts and theories. Furthermore, the authors believe that participation in book discussions reinforce the notion that learning can happen outside of a formal class setting, subsequently providing an extracurricular learning opportunity. Additionally, researchers Munakata (2009) and Reiley (2008) found that students exhibited improved communication skills and more reflective 
thinking following participation in book discussions.

The utilization of book discussions provides a skill set that may serve as an additional opportunity for growth in one's teaching pedagogy. Discussions of this sort can provide an enhanced understanding of educating students, a means for transmitting knowledge and transformation and extension of that knowledge as it pertains to the understanding of global issues (Larson, 1997).

\section{Program Description}

Sheryl Sandberg is a noted advocate of gender equality. Since delivering a 2010 TEDWomen address about how women unintentionally sabotage their own careers, Sandberg and her commentary on women as leaders has found a place on the global stage. Her book Lean In: Women, Work, and the Will to Lead explains why women need to "lean in" to gain confidence, develop skills, and become more comfortable as leaders. The book's message regarding empowerment has resonated with women from a multitude of ages, cultures, and backgrounds, thus being an ideal selection for this inaugural women and leadership book discussion.

Participants for this program were self-selected students, faculty, and staff. A copy of Sheryl Sandberg's Lean In was provided to each of the discussion participants one month in advance of the book discussion. The participants read the books on their own prior to the event. A facilitator led the discussion along with four featured panelists. These women with unique professional and personal experiences from diverse backgrounds shared their own leadership stories as a part of the discussion. These shared narratives provided insight regarding the panelists' leadership experiences in the context of the book. This shared storytelling approach provided the student participants with a sense of comfort and a feeling of safety to share their own leadership narratives. The facilitator utilized questions from the Lean In discussion guide for the discussion, which was held over a three-hour time span on campus. Pertinent questions from the guide included:

- Do you think it matters that men hold the majority of leadership positions?

- What would be different if anything, if there were more women in leadership positions?

- In what ways are women and girls dissuaded from pursuing their goals and becoming leaders?

Multi-faceted perspectives were brought to the discussion, with the backgrounds of the panelists ranging from a law school graduate who is now a stay-at-home mom to a former AT\&T executive and an education abroad program director at a public comprehensive university. Also on the panel were a public comprehensive university administrator and a retired public school system administrator.

The panelists provided a connection for the students to the lived experiences of female leaders. Students commented that the discussion was enriched by the panelists' presence and participation. The panelists' and students' exchange provided the students with the opportunity to hear leadership stories from a wide array of successful women leaders and to further engage in 
the exploration of leadership issues that the women encountered.

The discussion participants represented a diverse group of students ranging from traditional age students to adult learners and students from international and American backgrounds. Additionally the faculty and staff discussion participants brought a variety of perspectives to the discussion. Included among the faculty and staff participants were a sociologist, leadership studies faculty member, and a staff member who focuses on programming for students and their families. These diversified backgrounds brought forth divergent perspectives and experiences resulting in an opportunity to create a forum to engage in collective reflection and dialogue amongst those in attendance.

\section{Event Outcomes}

The success of book discussions and reading groups inspired the formulation of an opportunity for student engagement with women and leadership issues in the context of a book discussion. The resulting approach manifested in the form of a book discussion that I implemented at my institution. The context of this discussion was to provide an opportunity to discuss the subject of women and leadership from a multitude of perspectives. Subsequently, I conducted a qualitative assessment of the participants' book discussion experience to more clearly ascertain the possible benefits of book discussions as a pedagogical tool for a transformative learning experience about women and leadership issues.

Qualitative Assessment. I conducted a content analysis of the audio-recorded commentary from the discussion participants in an effort to illustrate the benefits of a book discussion experience in the exploration and study of leadership. My analysis illustrated thought patterns that featured an emphasis on women and leadership issues in a variety of contexts. Those contexts included exploring women and leadership issues as it pertains to global, generational, and leadership identity frameworks. Some of the salient comments surrounding women and leadership in a global context from the discussion included: "When I traveled to Nicaragua I found myself preaching a lot, telling women what they should be and shouldn't be doing. Reflecting back on what Sheryl said about making nudges and kind of working within your own context ...I soon came to realize that they were leaders in their lives, homes and they took charge in the way that they could." While another participant recognized the leadership capabilities of women in today's world, "Women today are at a prime time to make a difference in the world. It is our charge as women to make the world a better place by helping everybody else out." This commentary illuminated for me the students' clear understanding of the role that women play as leaders in the world in their respective societies and locales. This ability to recognize the value and worth in a multitude of displays of leadership is one that I hope to instill in my students as we explore leadership in a variety of contexts, particularly on the global front.

Perhaps some of the most telling accounts of women and leadership issues were centered on a generational context. I was pleased to have student participants from a range of generations. For the adult learners and traditional age students alike there was a great deal of reflection upon the impact of the era in which they had been raised. I found that the messages of their day played a significant role in their understanding of leadership. One participant had this to say: "When I was growing up, it wasn't about college; my parents told me if I waited to get married until after 
high school they would pay for my wedding. I was not encouraged to pursue higher education." While another participant described a similar upbringing in the late sixties indicating, "I grew up in a time when the boys were sent to school. I was told you don't need to go to school; you'll get married and someone will take care of you." Both of these participants are adult learners who have pursued their respective college educations after raising children and supporting spouses. Despite hearing messages that discouraged their pursuit of higher education and leadership opportunities, the students indicated that they always saw value in higher education and now relished the opportunity to pursue their own degrees. Although these women had maintained successful careers and raised families, they still struggled to see themselves as leaders. In my work as a leadership educator I feel that messages such as these are dangerously defeating to women and their ability to see themselves as leaders. I was surprised to hear this theme repeated from a millennial participant who shared the following: "I'd like to understand why it's so hard for my generation. I graduated from high school in 2012. I've watched so many girls hold themselves back; some decided to have families early and say they can't do anything else. It's strange for my generation because we had college pushed on us. " As we continue to guide students through an exploration of leadership and related issues, I think it is also critical that we engage students in conversations regarding confidence in themselves as leaders. Just as we expose our students to various ideologies regarding leadership styles, we must also help them to see that they too are reflected in these ideologies.

In a related context the theme of leadership identity arose. Participants discussed navigating their life experiences and the impact these experiences had upon their leadership identity. One participant stated, "I am trying to fashion my leadership skills appropriately without giving up on what I believe in." The area of leadership identity was best described as an exercise in balance. Some of the participants indicated that their various life stages had significantly impacted their identity as a leader, those who were caring for elderly parents and on the opposite end of the spectrum those caring for young children. These experiences impacted choices that the women made regarding the pursuit of leadership opportunities. While the aforementioned participant was tenuously defining herself as a leader, another participant confidently spoke about her identity as a leader saying; "throughout my life I have been a leader." This commentary was especially meaningful as it provided the opportunity for participants to share their own stories of success and coping mechanisms for navigating an evolving leadership identity. The student participants found this to be particularly helpful as they considered their own course of action for developing leadership plans. It really resonated with me that the students were able to reflect upon their own experiences and make sense of subsequent decisions they had made regarding leadership opportunities and how they perceived themselves as leaders.

\section{Conclusion and Recommendations}

According to Barstow (2003), when reading a text, the ways for making sense of that text are already in place. Barstow maintains that we can, however, attempt to alter the context of understanding that is already in place by reviewing the text from different angles and engaging in dialogue with others. It is through this method of expanding the mind that we develop new interpretive strategies to be introduced. New ways of making meaning can be a result of diverse perspectives within the group, or a facilitator who encourages readers to go beyond the scope of 
their own preconceived ways of understanding.

As an assistant professor of leadership studies I felt it vital to offer a setting for the candid exploration of leadership experiences. Subsequently, the inaugural book discussion has evolved into an opportunity to expand relationships amongst the participants. The women involved have developed meaningful networks. Due to the success of the event and participant demand, plans are under way to continue the book discussion series. As the academy seeks to educate students on becoming competent leaders, research regarding tools and methods by which faculty equip students with leadership skills becomes increasingly critical. It is essential to build upon the impact of projects such as this one through research that further supports and investigates the efficacy of best practices in developing future leaders.

\section{References}

Adler, N. J., Brody, L. W., \& Osland, J. S. (2000). The Women's Global Leadership Forum: Enhancing One Company's Global Leadership Capability. Human Resource Management, 39(2/3), 209. doi: 10.1002/1099-050X(200022/23)39:2/33.0.CO;2-Y

Barstow, J. (2003). Reading in Groups: Women's Clubs and College Literature Classes. Publishing Research Quarterly, 18(4), 3. doi:10.1007/s12109-003-0010-х

Boyer, E. L. (1997). Scholarship reconsidered: Priorities of the professoriate. San Francisco: Jossey Bass.

Larson, B. (1997). Influences on Social Studies Teachers' Use of Classroom Discussion. (Paper presented at the Annual Meeting of the College and University Faculty Assembly of the National Council for the Social Studies): Cincinnati, OH.

Long, E. (2003). Book Clubs: Women and the Uses of Reading in Everyday Life. Chicago: University of Chicago Press.

Munakata, M. (2009). Welcome to the math book club: A new approach to integrating mathematics, reading and writing. Primus, 15(3), 259-266.

Sandberg, S. (2013). Lean In: Women, Work and the Will to Lead. New York: Alfred A. Knopf.

Switzer, A. T., \& Barclay, L. A. (2012). Book Clubs: Best Practices in Promoting Critical

Thinking in Business Classes. Journal Of Business \& Finance Librarianship, 17(4), 328345. doi:10.1080/08963568.2012.712635

Werhane, P. (2007). Women Leaders in a Globalized World. Journal Of Business Ethics, 74(4), 425-435. doi:10.1007/s10551-007-9516-Z 


\section{Author Biography}

Dr. Heather I. Scott, an Assistant Professor of Leadership Studies at Kennesaw State University holds a bachelor's degree in theatre (Agnes Scott College), a master's of education (The University of Georgia), and a doctorate of philosophy in Educational Leadership (Mercer University). Her research interests include leadership and online teaching pedagogy. 